\title{
UMA BREVE ANÁLISE DA NARRATIVIDADE DOS FATOS PASSADOS E PRESENTES ENTRE A COMPREENSÃO EPISTEMOLÓGICA DA HISTÓRIA E DO JORNALISMO
}

\author{
A BRIEF ANALYSIS OF THE NARRATIVITY OF THE FACTS PAST AND \\ PRESENT AMONG AN EPISTEMOLOGICAL UNDERSTANDING OF HISTORY \\ AND JOURNALISM
}

\author{
Fernando Tadeu Germinatti ${ }^{1}$ \\ https://orcid.org/0000-0001-7711-5875 \\ Tatiane Pereira Souza ${ }^{2}$ \\ https://orcid.org/0000-0003-1164-2191
}

Recedo em: 18 jul. 2018.

Aceito em: 16 dez. 2020.

\begin{abstract}
RESUMO
A presente pesquisa, busca refletir as aproximações entre História e Jornalismo estudando o percurso teórico epistemológico de cada uma dessas áreas do conhecimento, tendo em mente as conexões, imbricações e também divergências possíveis de serem apontadas. Ao beberem da narratividade, tanto jornalismo quanto a história impõe em seus relatos objetividade intrínseca ao processo de interpretação dos fatos. Por meio de uma análise qualitativa se buscou em bibliografia física e digital, avaliar como os dois campos ( jornalismo e história ) de modo indireto e as vezes involuntário, dialogam entre si ao fazerem uso da narratividade literária.
\end{abstract}

Palavras-chave: História. Jornalismo. Narrativa. Discursos.

\begin{abstract}
This study research, must see some questions in this language and journalism estudating the routes of the knowledge of the knowledge of knowledge of knowledge, which must not, which must not, which are not, such as counts. To work of the narrative, sensitive journalism in the impact of object in the relatives object in intrainsecation to process of the interpretation of facts. Por meio de uma análise qualitativa é buscado em bibliografia física e digital, avaliando como os dois campos

\footnotetext{
1 Graduado em jornalismo pelo Centro Universitário de Rio Preto - UNIRP, pós graduado em história social pela Universidade Cândido Mendes - UCAM, pós graduado em Sociologia e Ensino de sociologia pelo Centro Universitário Claretiano - CEUCLAR e Graduando em Ciência Política pelo Centro Universitário Internacional - UNINTER. E-mail: Germinattifer@outlook.com.

2 Graduada em Pedagogia com Licenciatura Plena pelo Centro Universitário de Rio Preto ( UNIRP), graduação em Gestão Educacional pela mesma Universidade, mestra em Educação pela Universidade Federal de São Carlos ( UFSCAR) e Doutora em Ciências Sociais pela Universidade Estadual Paulista (UNESP). E-mail: tatianedoutora@gmail.com.
} 
de diálogo e história de modo indireto e as vezes involuntário, dialogam entre si e fazem uso da narratividade literária.

Keywords: Post-modernity. Globalization. Cultural identity.

\section{INTRODUÇÃO}

Durante todo o decorrer do século XIX, a literatura se consolidou como o lugar da nacionalidade, de modo que falar de sua origem se confundia com o tema da origem da brasilidade. Isto porque, após a Independência, surgiu a necessidade de sustentação de uma "essência" brasileira que se diferenciasse da portuguesa. Nessa seara, segundo o estudioso Traquina (2005), aspectos de cunho social favoreceram para a relativa autonomia e expansão do jornalismo no século XIX, mais propriamente falando, no fim do século, quando, em um momento político histórico, a paisagem e configuração da sociedade se altera, assim, portanto é dito que :

Seria principalmente nas últimas décadas do século XIX, surpreendida pela turbulência das transformações sociais, que a cultura letrada e a imprensa começariam decididamente a avançar para além das elites tradicionais. Nessa época, em ritmo acelerado, no compasso de um modo de vida que exporta capitais e invade rapidamente inúmeros espaços do planeta, a história da formação das metrópoles brasileiras multiplica o tempo e a experiência social (CRUZ, 2000, p. 42).

Já na segunda metade do século $X X$, ocorreu nas ciências humanas um fenômeno e/ou processo denominado de linguistic turn, também conhecido como "giro linguístico". Esse giro consistiu numa guinada das ciências humanas (sociologia, antropologia, história, etc.). É também nesse contexto de tentativa de legitimação como ciência, e também de mudança de perspectiva de escrita, trazendo novas opções de escolha, de abordagens, de relevância quanto ao objeto de análise das novas ciências humanas e sociais, em especial a História. Michel de Certeau argumenta que a História seria ao mesmo tempo uma disciplina, uma prática e uma escrita (CERTEAU,1982,p.66).

Portanto, em linhas gerais pode-se tomar o entendimento de que "a história é bem a ciência do passado, com a condição de saber que este passado se torna objeto da história, por uma reconstrução incessantemente reposta em causa" (LE GOFF, 2003, p. 26). Sendo assim, na visão historiográfica clássica, enquanto a história 
professa ser a "ciência do passado", o jornalismo estaria destinado a relatar os fatos presentes.

Ora, posto que enquanto ao jornalismo, ao mapear esse campo, Ana Paula Goulart Ribeiro e Micael Herschmann (2008, p. 13-26) registram que a Comunicação no Brasil estaria à mercê de um dado "presentismo", uma vez compreendido que grande parte dos estudos realizados no país privilegia aspectos e problemas relacionados à contemporaneidade, que por sua vez versam sobre as reações da destacada pós-modernidade, da globalização, novas tecnologias, novos meios de comunicação.

Concentrando as atenções no processo de construção das narrativas em torno dos fatos, tomando como ponto de partida a análise das situações e posicionamento subjetivo do jornalista e do historiador, assim, outro enfoque válido, é quanto ao sentido do processo narrativo, as considerações aqui propostas pressupõem levar em conta as especificidades presentes na literatura e no narrar, que indubitavelmente passam pelo crivo substantivo e interpretativo do pesquisador. A literatura afirma Antônio Candido, (1976, p. 25)

É um sistema vivo de obras, agindo umas sobre as outras e sobre os leitores;
e só vivem na medida em que estes a vivem, decifrando-a, aceitando-a,
deformando-a. [...] a obra de arte só está acabada no momento em que se
repercute e atua, porque sociologicamente, a arte é um sistema simbólico de
comunicação inter-humana. Ora, todo processo de comunicação pressupõe
um comunicante, no caso o artista; um comunicado, ou seja, a obra; um
comunicando, que é o público a que se dirige; graças a isso define-se o quarto
elemento do seu processo, isto é, o seu efeito.

É nesse sentido que pensando que as narrativas, sejam históricas ou literárias, ou outras, constroem uma representação acerca da realidade, procura-se compreender a produção e a recepção dos textos, entendendo que a escrita, a linguagem e a leitura são indivisíveis e estão contidas no texto. Portanto, é tangível que ao tratar as fronteiras dispostas entre o pesquisador jornalista e o historiador, cumpre-se dizer que andam pela narrativa para corroborar seus enunciados.

E se pensarmos bem, levando em consideração o conhecimento humano está em todas as suas formas ligado a e com linguagens (no sentido semiótico: verbais tanto quanto não-verbais) e processos de significação (semioses) (VAINFAS e CARDOSO, 1997, p. 40). Assim, a linguagem em sua representação está relacionada 
aos processos de produção de conteúdo, o que é bem delineado ao tratar-se das relações inquietas e desafiantes entre jornalismo, história e literatura.

\section{A TRÍADE DIALÓGICA ENTRE JORNALISMO, HISTÓRIA E LITERATURA}

Partindo do pressuposto de que a história como conhecimento é sempre uma representação do passado e que toda fonte documental para produzir esse conhecimento também o é, procuraremos apresentar aqui algumas reflexões acerca das relações estabelecidas entre a história e a literatura e certas ponderações teóricas e metodológicas sobre as possibilidades de emprego das fontes literárias na pesquisa histórica. "A história só existe no presente porque o passado deixou inscritos, no nosso aqui e agora, vestígios múltiplos que indicam a existência desse passado." (BARBOSA, 2010, p.11).

Para o historiador Roger Chartier (1990, p. 62-3), todo documento, seja ele literário ou de qualquer outro tipo, é representação do real que se apreende e não se pode desligar de sua realidade de texto construído pautado em regras próprias de produção inerentes a cada gênero de escrita, de testemunho que cria "um real" na própria "historicidade de sua produção e na intencionalidade da sua escrita". Para Chalhoub e Pereira (1998, p.7),

a proposta é historicizar a obra literária - seja ela conto, crônica, poesia ou
romance -, inseri-la no movimento da sociedade, investigar as suas redes de
interlocução social, destrinchar não a sua suposta autonomia em relação à
sociedade, mas sim a forma como constrói ou representa a sua relação com
a realidade social - algo que faz mesmo ao negar fazê-lo.

Num sentido próximo ao dos historiadores Chalhoub e Pereira, o jornalista Felipe Pena (2006) ao reler os discursos jornalísticos expõe as práticas libertárias contidas na ação narrativas, assim, afirma que jornalismo literário não significa somente distanciar-se das conveniências de uma sala de redação ou usar termos ficcionais em um livro-reportagem, mas especialmente:

[...] potencializar os recursos do jornalismo, ultrapassar os limites dos acontecimentos cotidianos, proporcionar visões amplas da realidade, exercer plenamente a cidadania, romper as correntes burocráticas do lead, evitar os definidores primários $e$, principalmente, garantir perenidade e profundidade aos relatos (PENA, 2006, p. 13). 
Nessa mesma esteira, Nicolau Sevcenko (2003), em seu trabalho sobre Literatura moderna brasileira (com foco nas obras de Euclides da Cunha e Lima Barreto), parte a defender que a Literatura e sua natureza comunicacional do discurso:

[...] constitui possivelmente a porção mais dúctil, o limite mais extremo do discurso, o espaço onde ele se expõe por inteiro, visando reproduzir-se, mas expondo-se igualmente à infiltração corrosiva da dúvida e da perplexidade (SEVCENKO, 2003, p. 28).

Para Jenkins (2009), esse é o caminho que a História deverá seguir para modernizar-se. Será necessário pensar sobre a natureza da história, bem como sobre a maneira que o seu discurso é estruturado, se é ou não possível uma compreensão objetiva do passado e por fim qual é a situação dos pareamentos (causa e efeito, semelhança e diferença, continuidade e mudança) que aparecem com frequência nas definições do que seja história. , o "passado é, portanto, uma dimensão permanente da consciência humana, um componente inevitável das instituições, valores e outros padrões da sociedade humana" (HOBSBAWM, 2013, p. 25).

Estudar o passado, bem como o presente, não deve se limitar às análises dos fatos e evidencias concretas, de forma parecida com oque se fazia na ciência positivista no início do século XX, uma vez que pensar historicamente pressupõe contextualizar os espaços sociais em uma série de fatos, eventos, ocorrências, costumes, instituições que se conformam como um fluxo - antes e depois (BARBOSA, 2007).

Nesta discussão teórica, uma distinção necessária a ser feita é entre história e seu passado. Embora o termo "história" possa abranger tanto os escritos dos historiadores quanto tudo aquilo que passou antes em todos os lugares, é preciso levar em consideração essa distinção. Para tanto, Jenkins (2009) estabeleceu "o passado como o objeto da atenção dos historiadores, a historiografia como a maneira pela qual os historiadores o abordam" (p. 25) e a palavra História para indicar o todo. Ainda que divaguem epistemologicamente, guardadas as diferenças teóricas e de cunho metodológico,

A natureza da literatura, por sua vez, parece ser outra e até oposta à do jornalismo. Trata se de dotar a linguagem verbal de uma dimensão em que ela não é meio, mas fim; tomá-la como matéria em si, portadora de potencialidades expressivas. Na literatura, a linguagem não é mera figurante, mas centro das atenções. Nesse sentido, se há algo para comunicar na 
literatura, esse algo só existe pelo poder conferido à conduta da própria linguagem. Não se trata de exatamente de afirmar que não existe mundo algum fora da experiência da linguagem. Mas de supor que para a realização literária, tal mundo só importará se o verbal que o transmitir estiver, por assim dizer, transmutado, recriado, destituído de sua função cotidiana e costumeira. Com isso, vem a constatação de que a razão de ser da literatura não é exatamente a comunicação. (BULHỖES, 2007:12).

De forma própria, como analisada por Marcelo Bulhões (2002), a literatura se molda aos anseios epistemológicos da história e do jornalismo, de modo que, dela é se instrumentalizada as condições discursiva para relato dos fatos, passados e/presentes. A sujeição representativa contida uma vez posto que tem-se assim, personificada pelo ato de interpretação dos fatos sentidos. Deste ponto, a literatura age "podendo desafiar ou até transgredir a concretude da existência dos seres e dos fenômenos" (BULHÕES, 2007, p.18).

Nessa seara, Lloyd Kramer (2001) expõe que a história nunca pode ser inteiramente separada da literatura ou da filosofia, ou de outras linguagens disciplinares, ainda que nunca seja idêntica a esses outros discursos. Desse modo, segundo o autor, "repensar as fronteiras da linguagem constitui um meio de repensar e ampliar as fronteiras da história" (KRAMER, 2001, p.140).

Visando exatamente o poderio contido na literatura, o historiador Hayden White, em seus estudos, não faz da literatura um artificio da história, mas o contrário, faz da história um artifício literário. Em relação às acusações da relativização causada por Hayden White (2001), no que tange as questões referentes à veracidade da história, como também, a tornar a história um gênero literário, podemos encontrar resposta na seguinte afirmação:

No intuito de antecipar algumas das objeções que os historiadores opõem muitas vezes ao argumento que segue, quero admitir desde já que os eventos históricos diferem dos eventos ficcionais nos modos pelos quais se convencionou caracterizar as suas diferenças desde Aristóteles. Os historiadores preocupam-se de eventos que podem ser atribuídos a situações específicas de tempo e espaço, eventos quesão (ou foram) em princípio observáveis ou perceptíveis, ao passo que os escritores imaginativos poetas, romancistas, dramaturgos - se ocupam tanto desse tipo de eventos quanto dos imaginados, hipotéticos ou inventados. O problema não é a natureza dos tipos de eventos com que se ocupam historiadores e escritores imaginativos. O que nos deveria interessar na discussão da 'literatura de fato' ou, como preferi chamar, das 'ficções da representação factual', é o grau em que o discurso do historiador e o do escritor imaginativo se sobrepõe, se assemelham, ou se correspondem mutuamente. Embora os historiadores e os escritores de ficção possam interessar-se por tipos diferentes de eventos, tanto as formas dos seus respectivos discursos como os seus objetivos na 
escrita são amiúde os mesmos. Além disso, a meu ver, pode se mostrar que as técnicas ou estratégias de que se valem na composição dos seus discursos são substancialmente as mesmas, por diferentes que possam parecer num nível puramente superficial, ou diccional, dos seus textos.

Faz-se mister salientar, que as proposições articuladas por White, em uma citação longa, é certo, é de suma imperatividade ao elencar por caminhos teóricos seu procedimento metódico, sinalizado no sentido de agrupar a problemática nas técnicas narrativas operadas por jornalistas e historiadores caminham para um rumo discursivo em que partem do ponto da análise contextual do fato

A primeira imposição do discurso consiste em prescrever como início aquilo
que na realidade é um ponto de chegada, ou mesmo um ponto de fuga da
pesquisa. Enquanto esta dá os seus primeiros passos na atualidade do lugar
social, e do aparelho institucional ou conceitual, determinados ambos, a
exposição segue uma ordem cronológica, Toma o mais anterior como ponto
de partida. Tomando-se um texto, a história obedece a uma segunda
imposição. A prioridade que a prática dá a uma tática de desvio, com relação
à base fornecida pelos modelos, parece contradita pelo fechamento do livro
ou do artigo. Enquanto a pesquisa é interminável, o texto deve ter um fim, e
esta estrutura de parada chega até a introdução, já organizada pelo dever de
terminar. (CERTEAU, 1982, p. 94)

Os historiadores podem, então, aprender algo com as técnicas narrativas de romancistas, mas não o suficiente para resolver todos os seus "problemas literários", já que os historiadores não são livres para inventar ações e pensamentos para personagens ou ainda, não são sequer livres para inventar personagens, "[...] além de ser improvável que sejam capazes de condensar os problemas de uma época na narrativa sobre uma família, como frequentemente o fizeram os romancistas" (BURKE, 1992, p. 340).

Destarte, Borges (2010) coloca de maneira sucinta, que a Literatura, seja ela na forma de crônica, conto ou romancese apresenta "[...] como uma configuração poética do real, que também agrega o imaginado, impondo-se como uma categoria de fonte especial para a história cultural de uma sociedade" (BORGES, 2010, p. 108). Para o historiador Jurandir Malerba (2009), a historiografia é um discurso escrito que se afirma verdadeiro - que os homens têm sustentado sobre o seu passado:

A maneira como as narrativas históricas são construídas, segundo os postulados narrativistas, e as conexões que elas estabelecem entre os eventos e as interpretações e explicações que apresentam, são assim vistas como construções impostas sobre o passado, antes que fundadas nos, limitadas aos ou respondíveis pelos fatos tais como expostos nas evidências. Do ponto de vista narrativista, os tropos e os gêneros literários empregados 
pelos historiadores prefiguram e determinam a visão, as interpretações e o sentido dos fatos. Pelo mesmo enfoque, eles também colocam as narrativas históricas na mesma categoria que discursos ficcionais de escritores e artistas, de modo que seria impossível fazer distinção entre história e ficção ou atribuir diferentes interpretações históricas na base de fatos ou evidências (Malerba, 2009, p.14).

A narrativa histórica descreve os acontecimentos contidos num registro "de modo a informar ao leitor o que deve ser tomado como ícone dos acontecimentos a fim de torná-los familiares a esse leitor" (WHITE, 1994, p. 105). Até mesmo no campo específico da narrativa historiográfica, podemos nos deparar com tais figuras da retórica e da poesia clássica como formas estruturais constituintes dos discursos em geral, como nos mostra a abordagem de White (1995). Importa, ainda, comentar que:

De igual modo, o tratamento da temporalidade permite incontáveis variações entre o respeito absoluto ao quadro cronológico, caracterizado por um desfilar contínuo do nascimento à morte da personagem biografada, e as liberdades do autor com o uso do tempo. O empenho em dar mais eficácia ao relato pode conduzir ao rompimento da linearidade cronológica e à adoção das múltiplas vozes narrativas que participam dos vários registros de temporalidade. O mais das vezes, o biógrafo procura alternar capítulos de tonalidade diacrônica com capítulos de tonalidade temática. Resulta daí um relato misto que procura reencontrar duas coerências de temporalidades diferentes, a da lógica própria à sucessão dos eventos e a que emana da unidade da pessoa resgatada pelo biógrafo. A narração biográfica não é, pois, como salienta Madelénat, homogênea. É, bem ao contrário, uma estrutura inelutavelmente compósita, uma convergência de relatos diversos enredados uns nos outros. Nisso lembra a escrita da história e do romance

De forma primorosa e própria, Hayden White (1995), sintetiza os caminhos percorridos pela narratividade em busca de significância os conjunto do texto narrado, por outras vias, o tratamento da natureza específica do relato, seja ele histórico ou jornalístico, vai calcar-se em bases argumentativas da estrutura do fato a ser narrado. Nesta imbricação epistemológica, o filósofo francês Pêcheux (1997), de forma sintética, vai lançar a palavra de que o enunciado tem sim inúmeras lacunas e variáveis subjetivas, expõe então que:

Todo enunciado é intrinsecamente suscetível de tornar se outro, diferente de si mesmo, se deslocar discursivamente de sentido para derivar par um outro (a não ser que a proibição da interpretação própria ao logicamente estável se exerça sobre ele explicitamente). Todo enunciado, toda seqüência de enunciados é, pois, lingüisticamente descritível como uma série (léxicosintaticamente determinada) de pontos de deriva possíveis, oferecendo lugar a interpretação. (PÊCHEUX, 1997, p. 53).

Dentro das vias de explanação argumentativa a respeito dos caminhos trilhados pela narratividade dos relatos e sua evocação própria de subjetividade em base 
interpretativa. Ora, Certamente, se nos situamos nas significações em uma mensagem são estabelecidas pelos significados de um código e é esse código que permite que a mensagem seja organizada (...)" (Heck, 1996, p.124).

Assim, imposta pelo jornalista e historiador, resta pois que ao beberem da mesma fonte epistemológica, um sentido representativo aflora permeado de significantes de fatos mutáveis e reavaliáveis. Apoiando-se em bases teóricas, se postas sobre a mesa, mediante arcabouço argumentativo do filósofo de Michel Foucault (1995), todo discurso é marcado por enunciados que o antecedem e o sucedem, integrantes de outros discursos.

Portanto, a chave para a discussão epistemológica proposta pelo artigo pode ser as formas discursivas, que explanação seus significados tanto no meio do jornalismo como da história, torna-se essencial para a propagação e divulgação dos fatos acontecidos, levando em consideração, seus sentidos. Para tanto, ao analisar os discursos levamos em conta suas especificidades (Foucault 2007).

Sem entrarmos ao conjunto teórico distinto de cada autor, num sentido próximo , o linguista teórico francês Roland Barthes, em sua obra $O$ discurso da história (1967), questiona se "essa narração [histórica] difere realmente, por algum traço específico, por uma pertinência indubitável, da narração imaginária, tal como se pode encontrar na epopeia, no romance, no drama?" (BARTHES, 2004: 164).

Em suma, tais intervenções propsotas refletem, de modo justo, as inferências postuladas pela narração e seu circulo imaginário jogado pela história do fato narrado. Evidentemente, quando tratadas sem suas particularidades tanto jornalismo quanto história se distinguem em suas afinidades e objetivos, e não poderia ser diferente, contudo, ao se guardar as diferenças teóricas e também metodológicas, vê-se uma amplitude de significações que devem e podem ser tomadas pelos dois campos de estudo como peça-chave em ampliar a complexidade e riqueza epistemológica de seus estudos.

\section{CONSIDERAÇÕES FINAIS}

À guisa de conclusão, a narrativa se mostra como elemento comum transpassando ambos os campos do saber, tanto o jornalismo como a história a 
utilizam como meio de instrumento metodológico, embora com fins distintos. O jornalismo se ocupada da literatura para narrar os fatos, acontecimentos diários, pautando-se na objetividade, posto que a disciplina histórica opera com a literatura uma via de criatividade, abrindo espaço para a narrativa de verdades, histórias, mitos.

\section{REFERÊNCIAS}

BARBOSA, Marialva. História cultural da imprensa - Brasil - 1800-1900. Rio de Janeiro: Mauad X, 2007.

Mauad X, 2010.

História cultural da imprensa - Brasil 1900-2000. Rio de Janeiro:

BARTHES, R. O discurso da história. In: Idem. O rumor da língua. Tradução de Mário Laranjeira. São Paulo: Martins Fontes, 2004a, p. 163-180.

BORGES, Valdeci Rezende. História e Literatura: Algumas Considerações. Goiás: Revista de Teoria da História, Ano 1, n. 3, junho/ 2010.

BUCCI, Eugênio. "A crítica de televisão". In: MARTINS, Maria Helena (Org.). Rumos da crítica. São Paulo: Editora Senac São Paulo: Itaú Cultural, 2000.

BULHÕES, Marcelo. Jornalismo e literatura em convergência. São Paulo: Ática, 2007

BURKE, Peter. A história dos acontecimentos e o renascimento da narrativa. In:BURKE, Peter (org.) A escrita da História: novas perspectivas. São Paulo: Unesp,

1992

CANDIDO, Antonio. Literatura e sociedade: estudos de teoria e história literária. São Paulo: Nacional, 1976.DELLEUZE, Gilles, GUATTARI, Félix. Mil Platôs: capitalismo e esquizofrenia. Tradução de Ana Lúcia de Oliveira. São Paulo: Editora 34, 2005.

CARDOSO, Ciro Flamarion; e VAINFAS, Ronaldo (Orgs). Domínios da história: ensaios de teoria e metodologia. Rio de Janeiro: Campus, 1997.

CERTEAU, Michel de. A Escrita da História. Rio de Janeiro: Forense, 1982

CRUZ, Heloísa de Faria. São Paulo em Papel e Tinta: periodismo e vida urbana 1890-1915. São Paulo: EDUC; FAPESP; Arquivo do Estado de São Paulo; Imprensa Oficial SP, 2000.

DOSSE, François. O desafio biográfico: escrever uma vida. São Paulo. Editora da Universidade Federal de São Paulo, 2009.

FOUCAULT, Michel. A Arqueologia do Saber. Rio de Janeiro: Forense Universitária, 1995. 
FOUCAULT, Michel. A Ordem do Discurso: aula inaugural no Collège de France, pronunciada em 2 de dezembro de 1970. 15. ed. São Paulo: Loyola, 2007

JENKINS, Keith. A História Repensada. 3. ed. Tradução de Mario Vilela. São Paulo: Contexto, 2009.

HECK, M. C. The ideological dimension of media messages. In S. Hall, D. Hobson, A. Lowe, \& P. Willis (eds.). Culture, media, language (pp. 122-127). London: Routledge, 1996.

HOBSBAWM, Eric. Sobre história. São Paulo Companhia das Letras, 2013.

LE GOFF, Jacques. História e memória. Campinas: Editora da UNICAMP, 2003.

MALERBA, Jurandir (Org). A História Escrita: teoria e história da historiografia. SãoPaulo: Contexto, 2009.

PÊCHEUX, M. O discurso: estrutura ou acontecimento. Trad. Eni Orlandi. 2 ed. Campinas, SP: Pontes, 1997.

PENA, Felipe. Jornalismo Literário. São Paulo: contexto, 2006.

RIBEIRO, Ana Paula Goulart ; HERSCHMANN, Micael (Orgs.). Comunicação e História: interfaces e novas abordagens. Rio de Janeiro: Mauad X, 2008.

TRAQUINA, Nelson. Teorias do Jornalismo - Porque as notícias são como são. 2. ed. Florianópolis: Insular, 2005.

VICCHIATTI, Carlos Alberto. Jornalismo: comunicação, literatura e compromisso social. São Paulo: Paulus, 2005.

WHITE, Hayden. Trópicos do Discurso: Ensaio sobre a Crítica da Cultura.Tradução de Alípio Correia de Franca Neto. 2 ed. São Paulo, Editora da USP, 2001, p.137. 